\section{Dr. Gladio Mena Salinas (1929-2011)}

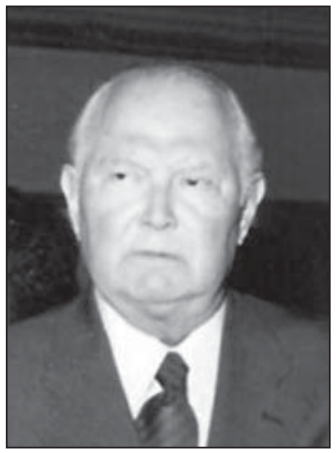

Con gran pesar, la comunidad de especialistas en Enfermedades Respiratorias del país, se enteró el 20 de marzo de 2011 del fallecimiento del Dr. Gladio Mena Salinas (Q.E.P.D.).

Gladio, nació el $1^{\circ}$ de enero de 1929 , e inició sus estudios de medicina en la Universidad de Concepción a los 17 años de edad. Al comienzo del $4^{\circ}$ año de su carrera, se trasladó a la Facultad de Medicina de la Universidad de Chile, ingresando como alumno a la Cátedra de Medicina del Profesor Rodolfo Armas Cruz.

Nos abandona, quien dedicó gran parte de su vida a la lucha contra la Tuberculosis en Chile. $\mathrm{Su}$ contacto con esta enfermedad fue muy temprano, cuando siendo estudiante perdió dos años de estudio debido a este mal, del cual recayó en dos oportunidades. En 1951 ya sano, se reincorporó a la Cátedra de Medicina del Prof. Hernán Alessandri recibiéndose de médico-cirujano en 1955, como recuerda su compañero de estudio y gran amigo, el Dr. Álvaro Yánez.

Después de realizar una beca de Medicina Interna con el Prof. Armas Cruz en el Hospital San Juan de Dios, probablemente su experiencia personal con la TBC, lo llevó a incorporarse en 1957 al naciente Centro de Enfermedades Bronco-Pulmonares (CEBP) dirigido por el Dr. Victorino Farga, que contaba con los Drs. Edgardo Carrasco, Isidoro Busel y Álvaro Yáñez como sus primeros colaboradores.

Fue una época de aprendizaje y de descubrimiento de la capacidad de trabajo en equipo. Gladio era un buen clínico, trabajador, perseverante, cooperador y disciplinado.

Con el tiempo el CEBP se hizo cargo de los enfermos de tuberculosis que se atendían en el Sanatorio Félix Bulnes y el Consultorio Andes. Gladio tomó este trabajo con una dedicación y sentimiento especial, ya que él conocía la enfermedad por experiencia propia, entendía la psicología del enfermo, era compasivo y comprometido con ellos.

El trabajo de este equipo, abrió nuevos caminos en el manejo y control de la enfermedad tuberculosa en Chile. Muchas de las medidas de avance y perfeccionamiento de las actividades de control, nacieron de la experiencia acumulada en el CEBP, la discusión en grupo de los casos nuevos y las auditorias de los casos más complejos. La Central de Tratamiento totalmente supervisado del CEBP, la primera del país y en América Latina, se extendió luego a los cinco consultorios de atención periférica del Área de Salud Occidente, donde los médicos de la institución concurrían dos veces a la semana a controlar a los pacientes en un lugar cercano a su residencia.

En 1966 su entusiasmo por la Epidemiología de la Tuberculosis lo impulsó a realizar un curso de perfeccionamiento de la Oficina Sanitaria Panamericana en Venezuela bajo la dirección del querido Dr. Iturbe. Volvió a Chile con mayor entusiasmo y encabezó las labores de educación de los enfermos con un flanelógrafo y la participación activa de enfermeras, asistentes sociales, psicólogos y educadores de la salud.

En 1968, el gran número de pacientes tuberculosos sin hogar, clientes de hospederías, nos impulsó a hacernos cargo de camas de Medicina del Sanatorio El Pino, para lo cual el Dr. Mena asumió la jefatura del Servicio de Medicina de dicho nosocomio, donde creó un policlínico y todas las unidades de apoyo requeridas. La experiencia en el Sanatorio El Pino le permitió al contingente médico del CEBP dar el gran paso de integrar definitivamente a la TBC a los Servicios de Medicina Interna del país que comenzó con la Cátedra de Medicina del Profesor Armas Cruz, que fue un visionario a este respecto, abriendo camas de su Servicio para la atención de pacientes TBC más complicados.

En octubre de 1973 el Dr. Mena fue agraciado con una beca viajera de la Organización Panamericana de la Salud (OPS), para visitar el Centro nacional argentino de Epidemiología de la tuberculosis, con sede en Recreo, Santa Fe, dirigido por el Dr. Antonio Pío y apoyado por el Dr. Karel Styblo, a quienes expuso la realidad del control de la enfermedad en Chile.

El $1^{\circ}$ de Abril de 1974 se trasladó al recién creado Instituto Nacional de Enfermedades Respiratorias y Cirugía Torácica (INERyCT), como jefe del Departamento de Epidemiología y 
Control de la Tuberculosis para el Área Oriente de Santiago, asumiendo además la Secretaria Regional de Control de la Tuberculosis, presidiendo las reuniones mensuales de esta institución, donde se tomaban las medidas para disminuir la morbi-mortalidad de la tuberculosis en la Región Metropolitana.

En 1980 asumió la jefatura del Servicio de Medicina del INERyCT, cargo que mantuvo hasta 1992, en que fue nombrado sub-Director del Instituto Nacional del Tórax, y que desempeñó con eficiencia hasta enero de 2003.

Además de su labor institucional tuvo una señera actividad docente como Profesor Asistente de Medicina de la Facultad de Medicina de la Universidad de Chile, participando directamente en las actividades de pregrado y postgrado del Instituto, contribuyendo a la formación de más de 200 becados en la especialidad de enfermedades respiratorias.

Otra de sus actividades relevantes fue su participación directa como docente $\mathrm{y} / \mathrm{o}$ director de los Cursos anuales de Epidemiología y Control de la TBC, donde formaron o renovaron sus conocimientos los jefes de Programa de Control de la TBC de las provincias del país.

Finalmente, debemos destacar el aporte de Gladio a la Sociedad Chilena de Enfermedades
Respiratorias, de la cual fue presidente en el bienio 1968-'69 y Editor adjunto entre 1989-' 90 de "Enfermedades del Tórax y Cirugía Torácica", antecesora de la Revista Chilena de Enfermedades Respiratorias. Su destacada contribución al desarrollo de la especialidad fue reconocida por la Sociedad Chilena de Enfermedades Respiratorias al otorgarle el nombramiento de miembro honorario, en noviembre de 2002.

Estimado Gladio, quienes te conocimos en el trabajo codo a codo en la generalización del tratamiento ambulatorio de la TBC, y en la dirección y sub-dirección de dos centros hospitalarios, no podemos dejar de destacar tu gran capacidad de trabajo, tu profundo conocimiento de la especialidad, y sobretodo tu caballerosidad, trato afable de los pacientes y de tu personal. Tu bonhomía y disposición para asumir con responsabilidad las tareas que te encomendaran.

Una cruel y recalcitrante artritis te impidió seguir adelante con tu deseo tan tangible de derrotar en Chile al flagelo de la Tuberculosis. Gladio, no estés triste cumpliste con una labor que todos te reconocemos. Descansa en paz.

\section{Dr. Edgardo Carrasco C. Dr. Álvaro Yáñez del V.}

